\title{
BMJ Open Prevalence of frailty in rural community-dwelling older adults in Kegalle district of Sri Lanka: a population-based cross-sectional study
}

\author{
Dhammika Deepani Siriwardhana, ${ }^{1,2}$ Manuj Chrishantha Weerasinghe, ${ }^{3}$ Greta Rait, ${ }^{1}$ \\ Milena Falcaro, ${ }^{1}$ Shaun Scholes, ${ }^{4}$ Kate R Walters ${ }^{1}$
}

To cite: Siriwardhana DD, Weerasinghe MC, Rait G, et al. Prevalence of frailty in rural community-dwelling older adults in Kegalle district of Sri Lanka: a population-based cross-sectional study. BMJ Open 2019;9:e026314. doi:10.1136/ bmjopen-2018-026314

- Prepublication history and additional material for this paper are available online. To view these files, please visit the journal online (http://dx.doi org/10.1136/bmjopen-2018026314).

Received 28 August 2018 Revised 16 November 2018 Accepted 19 December 2018

Check for updates

(C) Author(s) (or their employer(s)) 2019. Re-use permitted under CC BY-NC. No commercial re-use. See rights and permissions. Published by BMJ.

For numbered affiliations see end of article.

\section{Correspondence to}

Miss Dhammika

Deepani Siriwardhana;

deepani.siriwardhana.15@ucl. ac.uk

\section{ABSTRACT}

Objective Our main objective was to describe the prevalence and associated sociodemographic factors of frailty and pre-frailty in rural community-dwelling older adults in Kegalle district of Sri Lanka.

Design Community-based cross-sectional study.

Setting The study was conducted in rural areas of Kegalle district in Sri Lanka.

Participants A total of 746 community-dwelling older adults aged $\geq 60$ years were included in the study.

Results The prevalence of frailty and pre-frailty in rural Kegalle district was $15.2 \%(95 \% \mathrm{Cl} 12.3 \%$ to $18.6 \%)$ and $48.5 \%$ (95\% $\mathrm{Cl} 43.8 \%$ to $53.2 \%)$, respectively. We found a strong association between age and both frailty and pre-frailty. There were strong associations between longest-held occupation and frailty and education level and pre-frailty.

Conclusions The prevalence of frailty in this rural Sri Lankan older population was high compared with highincome and upper middle-income countries. The profile of health and social care services in Sri Lanka needs to address frailty and its consequences.

\section{INTRODUCTION}

Ageing involves physiological, psychological and social changes that directly affect the health and well-being of older adults. Frailty is an important age-related clinical syndrome commonly defined as a state of increased vulnerability to external stressors as a consequence of cumulative decline in many physiological systems during a lifetime. ${ }^{1}{ }^{2}$ It is widely recognised as a key issue for ageing populations worldwide, as it is associated with multiple adverse outcomes including hospitalisation, institutionalisation/dependency and premature mortality. ${ }^{3}$

Asia is home for the dominant share of the world's population ${ }^{4}$ and will become the region with the largest population of older adults in the coming decades. According to recent statistics, Thailand, DPR Korea and Sri Lanka have the highest proportion of

\section{Strengths and limitations of this study}

- We conducted the first population-based prevalence study on frailty using a representative sample of community-dwelling older adults in rural areas of Kegalle district of Sri Lanka.

- We employed a rigorous methodology and measures were taken to ensure the validity and reliability of data

- We compared age-adjusted prevalence of frailty in rural Sri Lanka with other Asian countries, and other middle-income countries worldwide.

- Sample only comprised rural older adults and the majority belonged to Sinhalese ethnicity.

- We excluded participants who could not give informed consent (eg, advanced stages of dementia) and were terminally ill. This might have underestimated the true frailty prevalence.

older persons (aged $\geq 60$ years) among the 11 member states that belong to WHO SouthEast Asia region. ${ }^{5}$ In 2012, the percentage of older adults aged $\geq 60$ years in Sri Lanka was $12.4 \% .{ }^{6}$ One out of every four persons is predicted to be an older person aged 60 years or above in Sri Lanka by $2041 .^{7}$ Thus, Sri Lanka is considered as one of the fastest growing ageing populations in SouthEast Asia. ${ }^{8}$

A recent meta-analysis on prevalence of frailty in low-income and middle-income countries (LMICs) reported a higher prevalence of frailty $(12.3 \%)$ and pre-frailty $(55.3 \%)$ in middle-income countries compared with high-income countries $(8.2 \%$, $43.9 \%) .{ }^{9}$ Few studies were found from Asia in general, particularly from WHO South-East Asia and low-income and lower middle-income countries. ${ }^{9}$ The pooled prevalence of frailty was $19.6 \%$ (95\% CI $15.4 \%$ to $24.3 \%$ ), in Latin America and the Caribbean with a range of $7.7 \%$ to $42.6 \%$ in the studies reviewed in another systematic review and 
meta-analysis. ${ }^{10}$ As a lower middle-income country with per capita gross domestic product of US $\$ 3857$ (2016), ${ }^{11}$ Sri Lanka needs to consider efficient and effective strategies to tackle the health, social and welfare issues of older adults. However, Sri Lanka, as with many LMICs that are ageing, has made little preparation to address the issues related to increased longevity. Moreover, there is a lack of underpinning empirical research to inform policy-makers on the emerging issues and the needs of the growing older population. Therefore, the main objective of this study was to describe the prevalence and associated sociodemographic factors of frailty and pre-frailty in community-dwelling older adults in rural areas of Kegalle district of Sri Lanka. We further explored how these compared with findings from other Asian countries and with other middle-income countries worldwide.

\section{METHODS}

\section{Study setting and study population}

We conducted a population-based cross-sectional study in rural areas of Kegalle district of Sri Lanka. Sri Lanka is divided into nine provinces encompassing 25 districts. The Kegalle district includes $4.1 \%$ of the Sri Lankan population. ${ }^{6}$ In addition to this administrative division, Sri Lanka has been categorised into three sectors (urban, rural and estate) on the basis of geographical location and availability of infrastructure facilities. ${ }^{6}$ Of the total population, $77.4 \%, 18.2 \%$ and $4.4 \%$ live in the rural, urban and estate sectors, respectively. ${ }^{6}$ In Kegalle district, the majority of people live in the rural sector $(91.3 \%)$ and the rest in the urban $(1.9 \%)$ and estate $(6.8 \%)$ sectors. ${ }^{6}$ The ethnic distribution of the district is $85.5 \%$ Sinhalese followed by Sri Lankan Moor (7.1\%), Indian Tamil (5.2\%), Sri Lankan Tamil (2.1\%) and other ethnicities $(0.1 \%){ }^{6}$

Study inclusion criteria were being an older adult aged $\geq 60$ years permanently residing in the rural areas. Older adults who were unable to give informed consent were excluded. This included people with severe dual hearing and vision impairment, aphasia, severe stages of dementia and those with unstable severe mental illness. Terminally ill older adults were also excluded.

\section{Sampling strategy and recruitment}

The sample size was calculated using the standard formula for prevalence studies. ${ }^{12}$ No published literature was found on the prevalence of frailty in Sri Lanka. We therefore used the prevalence of frailty in an Indian study of $11.4 \%^{13}$ to estimate the expected prevalence of frailty in rural Sri Lanka as $11 \%$. The absolute precision required on either side of the prevalence estimate was set as $3.5 \%$ and the $z$ statistics for the $95 \%$ level of confidence was 1.96 . To account for the multistage probability sampling technique, we inflated the estimated sample size by a design effect of $2.4,{ }^{14}$ giving a minimum sample of 737 participants. We used a complex sampling design: a three-stage probability sampling to recruit older adults representing the rural areas of the entire district (online supplementary appendix I). The final sample required was estimated as 750 participants.

\section{Data collection}

Data collection was conducted from 3 October to 23 December 2016. Five trained research assistants (nursing graduates) collected data, assisted by six field assistants. A pre-tested interviewer administered questionnaire collected data on sociodemographic, health-related, social activity and social support and lifestyle factors. The questionnaire was available in Sinhala and Tamil languages.

\section{Definition and assessment of frailty syndrome}

We used the Fried phenotype to define frailty status. ${ }^{2}$ All five phenotypic components proposed in the original study were retained, with small modifications to operationalise the shrinking and low physical activity components. Shrinking was defined as a body mass index $(\mathrm{BMI})<18.5 \mathrm{~kg} / \mathrm{m}^{2}$. Poor endurance and energy as indicated by self-reported exhaustion was assessed using two questions: 'I felt that everything I did was an effort' and 'I could not get going' from the Center for Epidemiologic Studies-Depression Scale. ${ }^{15}{ }^{16}$ If the answer was three or more days in the last week to either of these two questions, the respondent was considered as frail for this component. Falling in the lowest quintile of grip strength after adjusting for sex and BMI quartiles of the study population was considered as indicative of weakness. Participants' walking time in the highest time quintile after adjusting for sex and median standing height of the study population was considered as indicative of slowness. Individuals unable to perform the walking test were also considered as frail for this component. Low physical activity level was measured using the International Physical Activity Questionnaire (IPAQ) Short Form. ${ }^{17} 18$ Participants in the lowest quintile of weekly kilocalorie expenditure adjusted for sex were considered as frail for this component. A detailed description of how we measured the phenotypic components is provided in online supplementary appendix II. As recommended previously, ${ }^{2}$ participants were classified as frail if they had three or more frailty components, pre-frail (1-2 components) and robust/non-frail (0 components).

\section{Covariates}

Sociodemographic covariates of participants included sex, age at last birthday, ethnicity, marital status, living arrangements, education level (according to the International Standard Classification of Education ${ }^{19}$ ), longestheld income generation activity and subjective financial strain. ${ }^{20}$ We used the Sri Lanka Standard Classification of Occupation, ${ }^{21}$ based on the International Standard Classification of Occupations $2008,{ }^{22}$ to classify income generation activities. 


\section{Statistical analyses}

Data were double entered by two independent operators and checked for discrepancies using EpiData software V.3.1 and, if necessary, corrected with reference to the original questionnaires. All analyses were performed in Stata V.14 accounting for the complex survey design. ${ }^{23}$ Design weights were computed as the inverse of the inclusion probability of each participant to the sample. Subsequently, post-stratification weights were obtained by adjusting the design weights to match the population age and sex distribution of the district. Post-strata $(n=10)$ were defined by 5-year age categories (60-64; 65-69; 70-74; $75-79$; $\geq 80$ years) by sex using the information available from the latest census. ${ }^{6}$

We estimated the prevalence and corresponding $95 \%$ CI of frailty, pre-frailty and robust groups overall and by sociodemographic characteristics. The main outcome of interest in our study was ordinal (robust, pre-frail and frail). We initially fitted a multivariable ordinal logistic regression model to estimate the association between sociodemographic factors and frailty status. However, the proportional odds assumption underlying this model was not valid for our data, and we therefore used a multinomial logistic regression instead. Robust was chosen as the reference category. Unadjusted, age-adjusted and sex-adjusted, and multivariable-adjusted relative risk ratios and their corresponding 95\% CIs were derived. All statistical tests were two sided with a significance level set at 0.05 .

\section{Exploratory cross-country comparison}

The age-specific prevalence of frailty and pre-frailty in our weighted sample was compared with the random-effects pooled prevalence of frailty and pre-frailty obtained from meta analyses of studies in upper middle-income Asian countries $(\mathrm{n}=7555$; three studies from China and one study from Malaysia), Japan-a higher income Asian country ( $\mathrm{n}=10912$; three studies) —and upper middle-income Latin American countries $(\mathrm{n}=15773 ; 11$ studies from Brazil, 3 from Colombia and 2 studies from Mexico). The data required for these meta analyses were obtained from two published papers. ${ }^{924}$ Studies that used the Fried phenotype of frailty with five components where weakness and slowness components were measured objectively using grip strength and gait speed were included, as a valid comparison with our study assessment methods. The details of the included studies are presented in online supplementary appendix III.

\section{Patient and public involvement}

We did not include involvement of Sri Lankan older adults in the study design, as the study was developed in the UK as part of a Commonwealth Scholarship, with limited resources. We used standard study instruments and physical assessment tests, which had been developed elsewhere, and most of these have been cross-culturally adapted and validated for Sri Lankan population. Prior to our main study, we obtained feedback from 10 Sri Lankan older adults (from a different location) on the study processes, including how to phrase certain questions and order of administering the instruments. A plain language summary of overall study results will be produced in English and translated into Sinhala and Tamil languages, and we will discuss with public representatives the best way to present and disseminate this information.

Participation was voluntary and no incentives were provided.

This manuscript was written according to the STROBE (STrengthening the Reporting of OBservational studies in Epidemiology) statement. ${ }^{25}$

\section{RESULTS}

\section{Sociodemographic characteristics}

Data were collected from 746 out of 750 older adults approached (response rate $99.5 \%$ ). The age range of the participants was 60 to 94 years. The median (IQR) age was 68 (64-75) years in both the weighted and unweighted samples. In the weighted sample, $56.7 \%$ were women, $97.4 \%$ participants belonged to the Sinhalese ethnicity and $63.8 \%$ of participants had an education level below upper secondary. Table 1 presents the sociodemographic characteristics of the unweighted and weighted samples overall and by sex.

\section{Fried phenotypic frailty components}

Of all participants in the unweighted sample, nine did not have measurements of height and weight (needed for obtaining BMI) due to medical conditions (they could not stand independently). For these participants, we also could not use their grip strength data as BMI is required for calculating the grip strength cut-offs. Overall, out of the five phenotypic components, only unintentional weight loss and weakness were missing for nine participants. However, eight of them met the frailty criteria on all three available frailty components, so they were classified as frail. The other participant was excluded from subsequent analyses as with the partial information available we could not assign a frailty status with certainty.

For simplicity, from here onwards we will only present the results based on the weighted sample. The most prevalent frailty component in the overall sample was self-reported exhaustion $(37.5 \%)$ followed by weakness $(23.6 \%)$ (table 2).

\section{Overall prevalence of frailty and pre-frailty}

The prevalences of frailty, pre-frailty and robust among rural community-dwelling older adults in Kegalle district in 2016 were $15.2 \%$ (95\% CI $12.3 \%$ to $18.6 \%$ ), $48.5 \%$ (95\% CI $43.8 \%$ to $53.2 \%$ ) and $36.3 \%$ (95\% CI $32.4 \%$ to $40.2 \%)$, respectively.

\section{Prevalence of frailty and pre-frailty by sociodemographic characteristics}

The prevalence of frailty status by sociodemographic characteristics is presented in table 3 . The prevalence of frailty increased steeply with advancing age. Moreover, 3.8\% of 
Table 1 Sociodemographic characteristics of the unweighted and weighted study samples

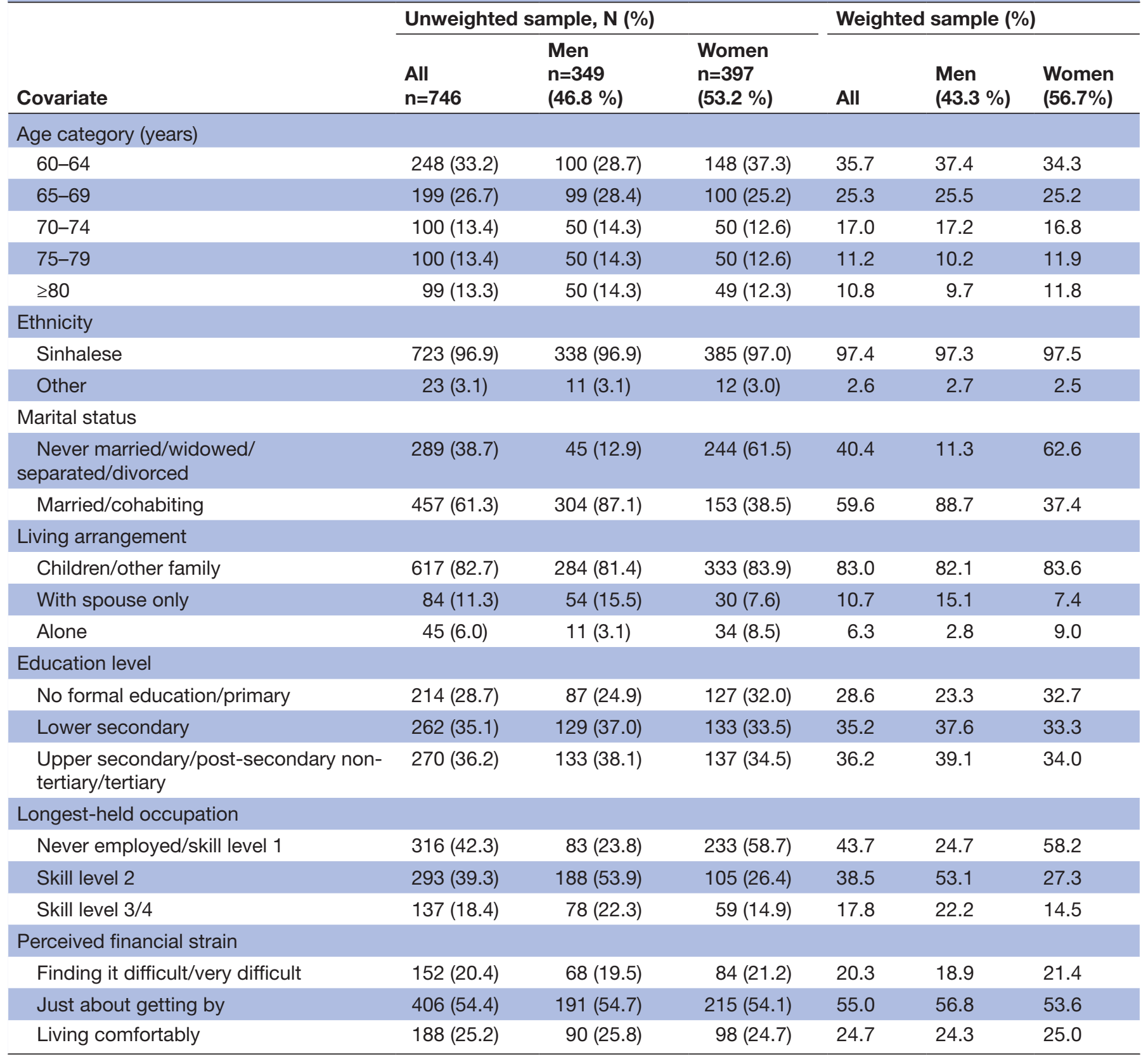

older adults aged 60-64years were classified as frail while nearly half $(47.9 \%)$ of those aged 80 years or older were considered as frail. The prevalence of frailty by sex did not vary markedly, though more women than men were pre-frail. A higher prevalence of frailty was observed in older adults with low education, those who have had low skilled occupations or never had employment and those who reported higher financial strain.

\section{Sociodemographic characteristics associated with frailty and} pre-frailty

Table 4 presents the results from the unadjusted, age-adjusted and sex-adjusted, and fully adjusted multinomial logistic regression models.
Frailty versus robust

In the fully adjusted model, the relative risk of being frail compared with being robust increased with advancing age. Similarly, the relative risk of being frail compared with being robust was 3.4 times higher in older adults who have never been employed or who had an occupation in the lowest skill level rather than the highest skill level.

Pre-frailty versus robust

In the fully adjusted model, the relative risk of being pre-frail compared with being robust was two-thirds lower for participants aged 60-64years relative to those aged 70-74years. Conversely, older adults in the lowest education group compared with those in the highest education 
Table 2 Prevalence of Fried phenotype frailty components and the total number of frailty components in the overall sample and by sex

Total (\%) Men (\%) Women (\%)

\begin{tabular}{lccc}
\hline $\begin{array}{l}\text { Fried's phenotype of } \\
\text { frailty component }\end{array}$ & & & \\
$\quad \begin{array}{l}\text { Shrinking (low BMI) } \\
\begin{array}{l}\text { Self-reported } \\
\text { exhaustion }\end{array}\end{array}$ & 18.2 & 20.2 & 16.6 \\
$\begin{array}{l}\text { Weakness (low grip } \\
\text { strength) }\end{array}$ & 23.6 & 19.6 & 26.6 \\
$\begin{array}{l}\text { Slowness (low gait } \\
\text { speed) }\end{array}$ & 19.6 & 18.7 & 20.3 \\
$\quad$ Low physical activity & 19.2 & 17.4 & 20.5 \\
\hline $\begin{array}{l}\text { Total no of frailty } \\
\text { components }\end{array}$ & & & \\
\hline 0 & 36.2 & 41.3 & 32.3 \\
\hline 1 & 30.8 & 29.7 & 31.6 \\
\hline 2 & 17.8 & 14.7 & 20.2 \\
\hline 3 & 10.5 & 10.4 & 10.6 \\
\hline 4 & 4.2 & 3.0 & 5.0 \\
\hline 5 & 0.5 & 0.8 & 0.3 \\
\hline
\end{tabular}

BMI, body mass index.

group had an approximately 2.4 times higher risk of being pre-frail compared with being robust.

\section{Supplementary exploratory analysis: cross-country comparison of prevalence of frailty and pre-frailty}

Figure 1 compares the age-specific prevalence of frailty in the rural areas of Kegalle district of Sri Lanka with the pooled prevalence of frailty in other comparable countries with data available: upper middle-income Asian countries (China and Malaysia), high-income Asian country (Japan) and upper middle-income Latin American countries (Brazil, Colombia and Mexico). Except for the age group 60-64years, prevalence of frailty across all the other age groups was higher in the rural areas of Kegalle district of Sri Lanka. The prevalence was higher in the older 75-79years and $\geq 80$ years age categories. With regard to pre-frailty, the prevalence rates were relatively similar across countries (figure 2 ).

\section{DISCUSSION}

\section{Summary of main findings}

To our knowledge, this is the first study conducted in Sri Lanka to investigate the epidemiology of frailty using the Fried frailty phenotype. ${ }^{2}$ The prevalence of frailty and pre-frailty among rural community-dwelling older adults aged $\geq 60$ years in Kegalle district in 2016 was estimated as $15.2 \%$ (95\% CI $12.3 \%$ to $18.6 \%$ ) and $48.5 \%$ (95\% CI $43.8 \%$ to $53.2 \%$ ), respectively. Nearly half of those aged $\geq 80$ years were frail. We found no evidence of an association between sex and being frail or pre-frail in any regression model. In the multivariable-adjusted model, increasing age and having never been employed or having had a low-skilled occupation increased the relative risk of being frail compared with being robust. Being in the lowest education level increased the relative risk of being pre-frail compared with robust. In exploratory analyses, the prevalence of frailty appeared to be higher in Sri Lanka across all the age categories except 60-64 years when compared with the pooled prevalence of upper middle-income Asian countries, Japan and upper middle-income Latin American countries.

\section{Comparison with existing literature}

Frailty is an important clinical syndrome which predicts numerous adverse health outcomes in later life; however, there is a paucity of epidemiological research from Asian countries compared with the West. The majority of Asian studies are from high-income economies with few from WHO South-East Asia. India was a study site of two multicountry studies ${ }^{1326}$ and there were three small studies from Pune, India, ${ }^{27} \mathrm{Nepal}^{28}$ and Nakhon Pathom, Thailand. ${ }^{29}$ The reported prevalence of frailty in these studies ranged from $56.9 \%$ (frailty index ${ }^{26}$ to $11.4 \%$ (Fried phenotype with four components). ${ }^{13}$ The use of different frailty assessment methods and heterogeneity in the minimum recruitment age make it difficult to compare the prevalence of frailty between studies. A small community-based study of older adults ( $\geq 65$ years) in Pune, India ${ }^{27}$ used Fried phenotype, a similar assessment method to ours but with Cardiovascular Health Study (CHS) cut-offs ${ }^{2}$ for grip strength and gait speed, and found a prevalence of frailty and pre-frailty of $26.0 \%$ and $63.6 \%$, respectively. ${ }^{27}$ The corresponding prevalence of frailty and pre-frailty in our study after restricting the sample to those aged $\geq 65$ years and after applying the same CHS grip strength and gait speed cut-offs was $34.6 \%$ (95\% CI $29.3 \%$ to $40.4 \%$ ) and $49.7 \%$ (95\% CI $44.6 \%$ to $54.9 \%$ ). This difference may be due to the shorter life expectancy in India ${ }^{30}$ compared with Sri Lanka ${ }^{31}$ and more highly educated people living in an urbanised area in the Indian study. ${ }^{27}$

In our study, the prevalence of frailty in older adults aged $\geq 65$ years in Sri Lanka was $21.5 \%$ using population-specific grip strength and gait speed cut-offs. This is similar to a small study in Thailand $(22.7 \%),{ }^{29}$ but much higher than the pooled prevalence of frailty reported in high-income $(8.2 \%)$ and upper middle-income $(11.8 \%)$ countries using the same frailty assessment method and the same minimum recruitment age. ${ }^{9}$ This finding supports existing literature showing a strong relationship between national economic indicators and a country's level of frailty and fitness. ${ }^{32}$

We conducted our study in rural areas of Kegalle district. However, in Sri Lankan context, rural classification is itself problematic to some extent since semiurban areas where people have access to many facilities and good infrastructure are also classified as rural. This applies to Kegalle district too. Lower prevalence of frailty 
Table 3 Distribution of frailty statuses across sociodemographic characteristics

\begin{tabular}{|c|c|c|c|}
\hline \multirow[b]{2}{*}{ Covariates } & \multicolumn{3}{|c|}{ Prevalence $(95 \% \mathrm{Cl}), \%$} \\
\hline & Robust & Pre-frail & Frail \\
\hline \multicolumn{4}{|l|}{ Sex } \\
\hline Male & 41.3 (36.2 to 46.6 ) & 44.4 (39.3 to 49.5$)$ & 14.3 (10.9 to 18.3$)$ \\
\hline Female & 32.4 (26.9 to 38.2$)$ & 51.6 (44.0 to 59.0$)$ & $16.0(11.8$ to 21.1$)$ \\
\hline \multicolumn{4}{|l|}{ Age group (years) } \\
\hline $60-64$ & 55.0 (45.2 to 64.4$)$ & 41.1 (32.3 to 50.5$)$ & $3.8(1.7$ to 7.9$)$ \\
\hline $65-69$ & 38.9 (27.6 to 51.5$)$ & 51.0 (39.6 to 62.2) & $10.0(5.6$ to 17.2$)$ \\
\hline $70-74$ & 25.6 (16.4 to 37.7$)$ & 58.4 (47.7 to 68.2$)$ & 15.9 (8.6 to 27.4$)$ \\
\hline $75-79$ & $12.4(6.3$ to 22.9$)$ & 56.9 (43.0 to 69.7$)$ & 30.7 (19.3 to 44.9$)$ \\
\hline$\geq 80$ & $9.3(4.2$ to 19.3$)$ & 42.7 (28.4 to 58.3$)$ & 47.9 (33.1 to 63.0$)$ \\
\hline \multicolumn{4}{|l|}{ Marital status } \\
\hline Married/cohabiting & 42.6 (37.1 to 48.3$)$ & 45.9 (41.3 to 50.5$)$ & 11.5 (7.9 to 16.2$)$ \\
\hline Never married/widowed/separated/divorced & 26.8 (20.6 to 34.0 ) & 52.4 (44.4 to 60.1$)$ & 20.8 (14.8 to 28.4 ) \\
\hline \multicolumn{4}{|l|}{ Living arrangement } \\
\hline Children/other family & 36.0 (32.0 to 40.3 ) & 47.9 (42.9 to 52.6$)$ & 16.1 (12.7 to 20.1$)$ \\
\hline With spouse & 42.9 (27.5 to 59.7$)$ & 45.9 (30.4 to 62.1$)$ & $11.2(4.7$ to 24.0$)$ \\
\hline Alone & 26.8 (14.6 to 43.9$)$ & $62.2(38.1$ to 81.4$)$ & $11.0(2.1$ to 41.3$)$ \\
\hline \multicolumn{4}{|l|}{ Education level } \\
\hline No formal education/primary & $21.0(14.0$ to 30.0$)$ & 55.4 (46.8 to 63.7$)$ & 23.6 (16.4 to 32.6$)$ \\
\hline Lower secondary & 35.8 (29.5 to 42.5$)$ & 49.3 (42.1 to 56.3$)$ & 14.9 (9.9 to 21.8$)$ \\
\hline $\begin{array}{l}\text { Upper secondary/post-secondary non-tertiary/ } \\
\text { tertiary) }\end{array}$ & 48.8 (41.9 to 55.7$)$ & $42.2(34.7$ to 50.1$)$ & $8.9(5.4$ to 14.2$)$ \\
\hline \multicolumn{4}{|l|}{ Longest-held occupation } \\
\hline Never employed/skill level 1 & 29.5 (23.5 to 36.3 ) & 49.4 (43.3 to 55.4$)$ & 21.1 (16.2 to 26.8 ) \\
\hline Skill level 2 & 38.5 (31.5 to 46.0$)$ & 49.1 (41.5 to 56.6 ) & 12.4 (8.2 to 18.2$)$ \\
\hline Skill level 3/4 & 47.9 (39.2 to 56.7$)$ & 45.1 (35.8 to 54.6$)$ & $7.0(3.3$ to 14.1$)$ \\
\hline \multicolumn{4}{|l|}{ Perceived financial strain } \\
\hline Finding it difficult/very difficult & 26.7 (18.8 to 36.2$)$ & 54.0 (44.1 to 63.6$)$ & $19.3(13.3$ to 27.0$)$ \\
\hline Just about getting by & 36.1 (31.0 to 41.5 ) & 48.7 (42.6 to 54.7 ) & $15.2(11.7$ to 19.3$)$ \\
\hline Living comfortably & 44.5 (35.7 to 53.5 ) & 43.5 (32.6 to 54.9$)$ & $12.0(6.4$ to 21.3$)$ \\
\hline
\end{tabular}

was found among three studies conducted in rural areas of coffee-growing zones of the Colombian Andes mountains $(12.2 \%),{ }^{33}$ Mexico $(10.7 \%)^{34}$ and Turkey $(7.1 \%)^{35}$ compared with our study with similar frailty assessment method. However, both the Colombian and Turkish studies used non-probability sampling techniques (voluntary participation and convenience sampling). Voluntary participation might have underestimated the true prevalence, particularly if people with mobility limitations were less likely to take part in the study. The minimum recruitment age of the participants of these studies were $\geq 60,{ }^{33}$ $\geq 70^{34}$ and $\geq 65^{35}$ years, respectively.

In addition to the true variation of frailty prevalence rates across different populations, and differences in setting (urban/rural), these differences could also depend on methodological issues, for example, how phenotypic components are operationalised, which cut-offs are used, inclusion and exclusion criteria used to define the study population, and the way missing data of frailty components are handled. In keeping with many studies using the Fried phenotype, ${ }^{36}$ we used BMI $<18.5 \mathrm{~kg} / \mathrm{m}^{2}$ to operationalise 'shrinking', as we did not have access to serial weight measurements to objectively assess weight loss. For physical activity, we used the culturally adapted IPAQ as suitable for a Sri Lankan population unlike the original measure. ${ }^{37}$ The instrument used could be sensitive to cultural effects when translated into different languages and interpretation. ${ }^{38}$ Many studies included in the Latin American upper middle-income countries meta-analyses of this paper applied more restrictive inclusion criteria, which might have underestimated the true prevalence rates.

Age and female sex are two well-known biological risk factors of frailty ${ }^{39}$; however, we found an age but no sex difference in frailty or pre-frailty. A recent systematic review of longitudinal studies also found both an 


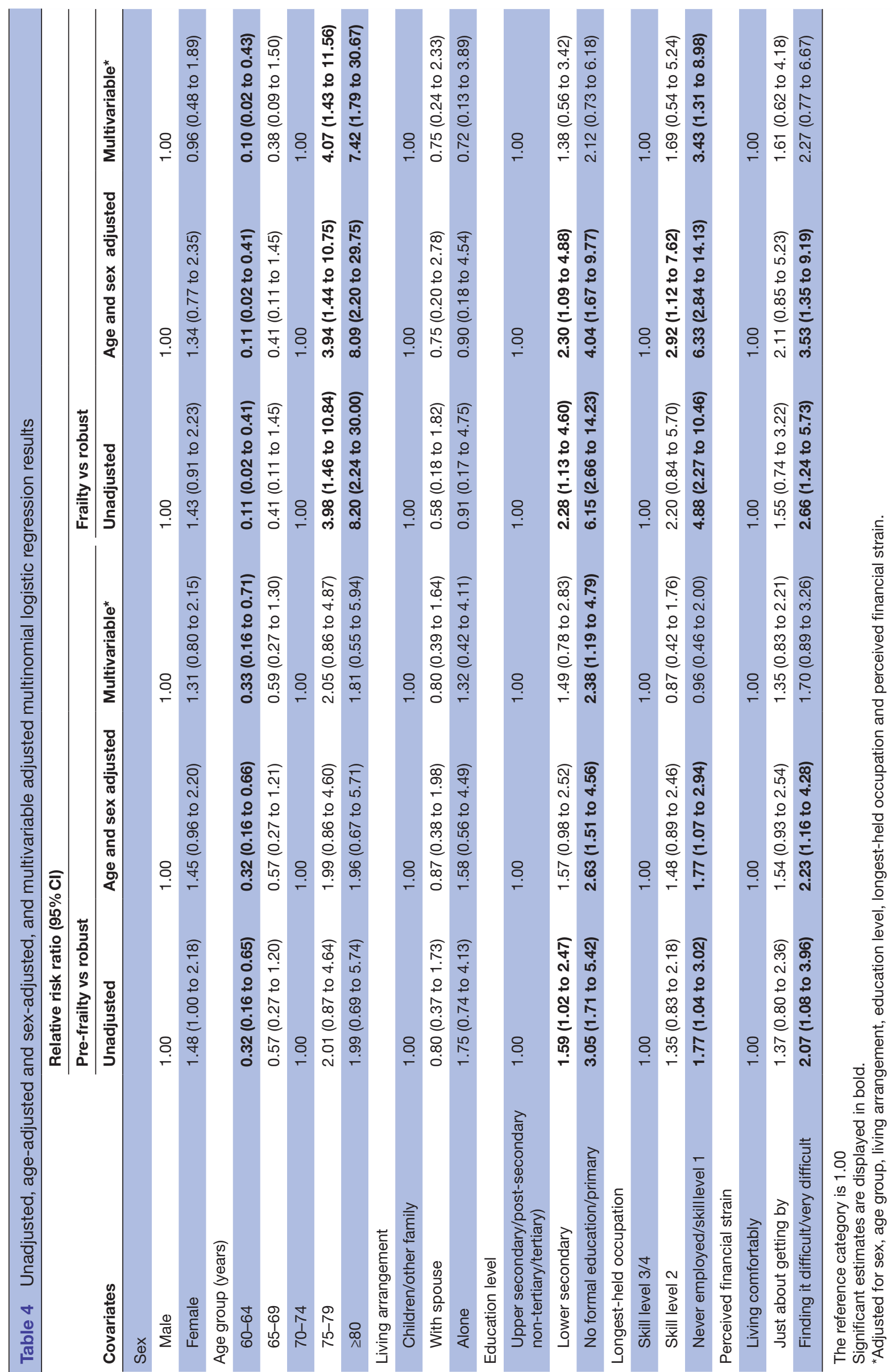

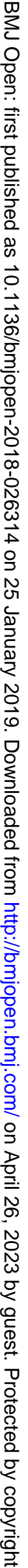




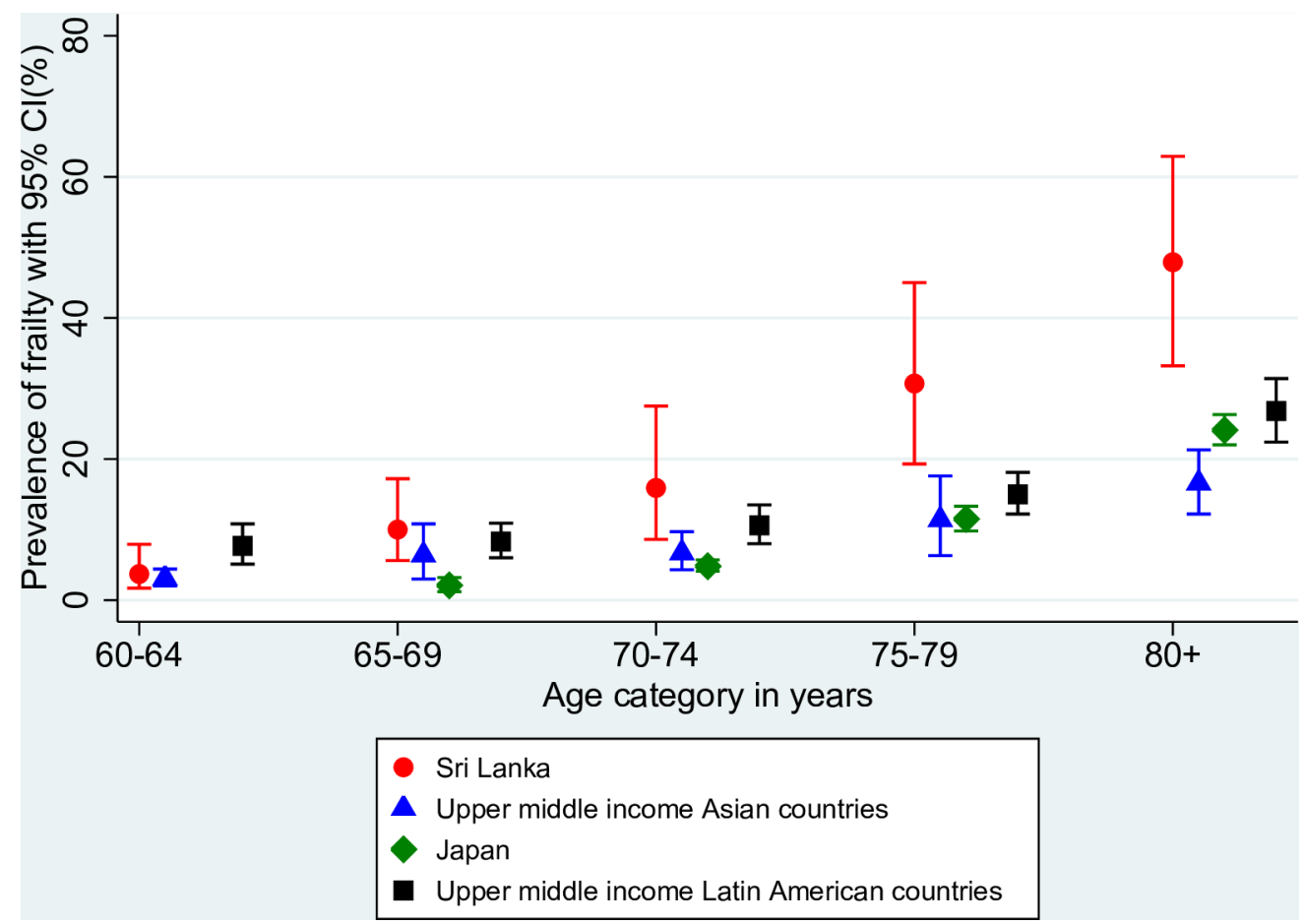

Figure 1 Comparison of age-specific prevalence of frailty in Sri Lanka with the pooled prevalence estimates of upper middleincome Asian countries, Japan and upper middle-income Latin American countries.

association and no association between sex and incident or increased risk of frailty. ${ }^{39}$ In this review, two studies reported female sex as a risk factor for frailty ${ }^{40} 41$ while two studies reported no association. ${ }^{42} 43$ A strong association between longest-held occupation and frailty and education level and pre-frailty was found in our study. Aforementioned systematic review based on longitudinal studies found studies reporting both positive and no association between level of education and frailty. ${ }^{39}$

\section{Strengths and limitations}

We conducted the first large population-based study on frailty with a regional representative sample of rural community-dwelling older adults in Kegalle district of Sri

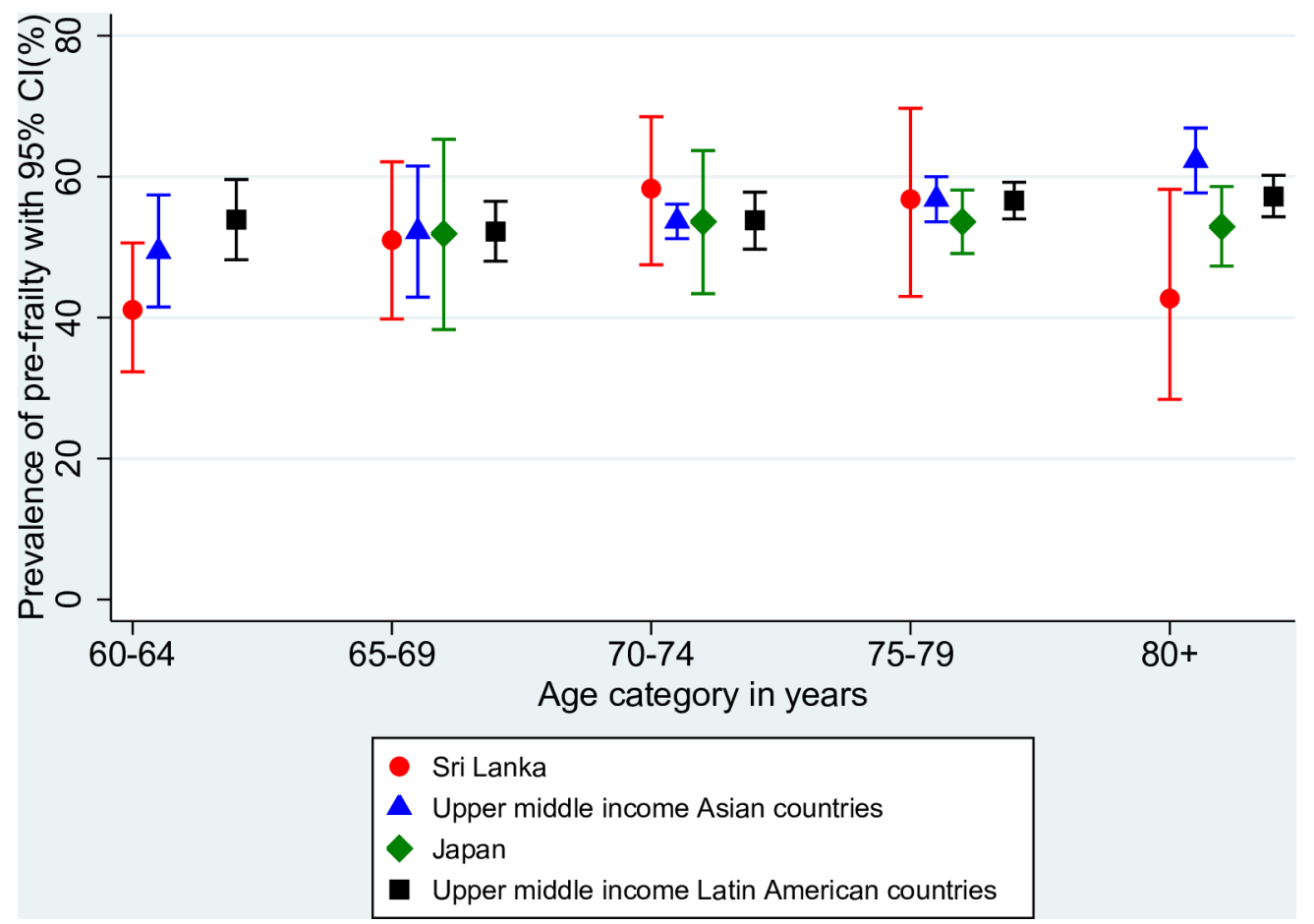

Figure 2 Comparison of age-specific prevalence of pre-frailty in Sri Lanka with the pooled prevalence estimates of upper middle-income Asian countries, Japan and upper middle-income Latin American countries. 
Lanka. We followed rigorous methodology and measures were taken to improve the validity and reliability of data. The intra-rater reliability of anthropometric measurements (height and weight) and physical performance tests (grip strength and walking time) were excellent (intraclass correlation $>0.9$ ). The response rate was extremely high $(99.5 \%)$. Our analyses involved a crosscountry comparison of frailty across income classification and geographical regions. Limitations include that the sample only comprised rural older adults and the majority belonged to Sinhalese ethnicity. Therefore, the results are likely not generalisable to urban and estate sectors and other ethnicities. The prevalence of frailty could be underestimated in our study as we excluded participants who could not give informed consent and those who were terminally ill. However, the number of excluded participants was very small and we were less restrictive than other studies. Some questions, for example, physical activity and self-reported exhaustion, could be affected by recall bias.

With regard to our cross-country comparison, it should be noted that our findings are based on a rural sample, and while the population of Sri Lanka is predominantly rural, this may not reflect the prevalence of frailty in urban and estate sectors in Sri Lanka. Furthermore, in the comparator country samples, it would be ideal if we had representative country-level data on the prevalence of frailty for this analysis. However, with the exception China, we were unable to find any nationally representative samples, and we therefore calculated pooled estimates of frailty and pre-frailty from studies conducted with regional samples. Moreover, studies included in this comparison have used both urban and rural samples. We have indicated the exact study setting and whether the sample is urban/rural/both/uncertain in online supplementary appendix III. We performed this analysis for exploratory purposes only and hence needs to be interpreted cautiously.

\section{Implications for public health}

The Sri Lankan health system is a well-known example of the provision of good healthcare at low cost. ${ }^{44}$ Around $70 \%$ of the disease burden in the country is due to non-communicable diseases (NCDs). ${ }^{45}$ The rapidly ageing population is contributing to increases in the prevalence of NCDs which is a huge challenge to the country's health system. Frailty and multimorbidity (multiple coexisting NCDs) are closely linked. Recently, guidelines have been introduced for the management of frailty in Asia-Pacific. ${ }^{46}$ Therefore, findings of this study are important to healthcare planners to quantify the extent of frailty and be prepared for establishing appropriate health and social services for older adults with frailty and multiple NCDs. The existing profile of health and social care services in Sri Lanka needs adjustments to meet the needs of age-related illness and care. Further improvements in geriatrics and gerontology disciplines are an urgent need. Investing in elderly health is important to mitigate the medical and social implications of ageing.

\section{CONCLUSION}

The prevalence of frailty in this rural Sri Lankan older population was high in comparison with both higher-income and upper middle-income countries. There has been little research conducted on frailty in low-income and lower middle-income countries. Identifying the scale of the problem will help these growing economies to prepare and respond to the challenges associated with increasing longevity.

\section{Author affiliations}

${ }^{1}$ Research Department of Primary Care and Population Health, University College London, London, UK

${ }^{2}$ Department of Disability Studies, Faculty of Medicine, University of Kelaniya, Ragama, Sri Lanka

${ }^{3}$ Department of Community Medicine, Faculty of Medicine, University of Colombo, Colombo, Sri Lanka

${ }^{4}$ Research Department of Epidemiology and Public Health, University College London, London, UK

Acknowledgements Authors acknowledge all the participants of this study who kindly gave their time and effort to respond to the questionnaire. We also thank the assistance provided by the Director General of Health Services, Provincial Director of Health Services-Sabaragamuwa province, District Secretary and Regional Director of Health Services-Kegalle district, all the Divisional secretaries and the Grama Niladhari officers of the respective areas investigated in this study. We would like to thank Mrs. Krishna Kurunathapillai for performing theTamil translation of all the study instruments. We would also like to thank the research assistants (HPM Hewavitharane, PGIP Udayakumara, DMN Kumara, APA Jayasinghe, MVJD Abeyrathna) and the field assistants (HKP Ariyadasa, KDSS Dissanayaka, WGC Pussallamada, GRKM Rathnasiri, WST Weerasinghe, RJS Dharmawansha, WRP Wijenayake, VPDI Danarathna, RGRD Anuruddha) for their invaluable support with data collection. We would also like to acknowledge Professor AR Wickremasinghe, Department of Public Health, Faculty of Medicine, University of Kelaniya, Sri Lanka for his invaluable guidance on data cleaning process. We thank the Department of Community Medicine, Faculty of Medicine, University of Colombo for handling finances and arranging logistics for the field study.

Contributors DDS, KRW, MCW and GR conceived and designed the study. DDS and MCW collected the data. DDS, MF and SS analysed the data. DDS drafted the manuscript. KRW, MCW, GR, MF and SS critically revised the manuscript.

Funding DDS (corresponding author) is a commonwealth Scholar, funded by UK government (LKCS-2015-678).

Disclaimer The funder had no role in study design, data collection, data analysis, interpretation, drafting the paper or decision to publish.

Competing interests None declared.

Patient consent for publication Obtained.

Ethics approval Ethics approval for this study was obtained from ethics review committees at University College London (project ID: 8155/001) and University of Colombo, Sri Lanka (protocol no. EC-16-071).

Provenance and peer review Not commissioned; externally peer reviewed.

Data sharing statement All relevant data are within the paper and supplementary file.

Open access This is an open access article distributed in accordance with the Creative Commons Attribution Non Commercial (CC BY-NC 4.0) license, which permits others to distribute, remix, adapt, build upon this work non-commercially, and license their derivative works on different terms, provided the original work is properly cited, appropriate credit is given, any changes made indicated, and the use is non-commercial. See: http:// creativecommons.org/licenses/by-nc/4.0/. 


\section{REFERENCES}

1. Clegg A, Young J, Iliffe S, et al. Frailty in elderly people. The Lancet 2013;381:752-62.

2. Fried LP, Tangen CM, Walston J, et al. Frailty in older adults: evidence for a phenotype. J Gerontol A Biol Sci Med Sci 2001;56:M146-57.

3. Vermeiren S, Vella-Azzopardi R, Beckwée D, et al. Frailty and the prediction of negative health outcomes: a meta-analysis. J Am Med Dir Assoc 2016;17:1163.e1-17.

4. Bloom DE. 7 billion and counting. Science 2011;333:562-9.

5. World Health Organization. Measuring Core Health Indicators in the South-East Asia Region 2014. 2015.

6. Department of Census and Statistics: Ministry of Policy Planning and Economic Affairs. Census of Population and Housing 2012. 2015.

7. De silva WI. A population projection of Sri Lanka for the Millenium, 2001-2101: trends and implications. 2007.

8. Rajapakse S, Maithripala C, Ibrahim S, et al. Disease patterns and care of older people in Sri Lanka. Indian J Gerontol 2012;26:351-66.

9. Siriwardhana DD, Hardoon S, Rait G, et al. Prevalence of frailty and prefrailty among community-dwelling older adults in low-income and middle-income countries: a systematic review and meta-analysis. BMJ Open 2018;8:e018195.

10. Da Mata FA, Pereira PP, Andrade KR, et al. Prevalence of frailty in Latin America and the Caribbean: a systematic review and metaanalysis. PLoS One 2016;11:e0160019

11. Central Bank of Sri Lanka. Annual Report 2017. Colombo 01, Sri Lanka: Central Bank of Sri Lanka, 2018.

12. Lemeshow S, Hosmer DW, Klar J, et al. Adequacy of sample size in health studies. Baffins Lane, Chichester, West Sussex: England John Wiley \& Sons Ltd, 1990

13. At J, Bryce R, Prina M, et al. Frailty and the prediction of dependence and mortality in low- and middle-income countries: a 10/66 population-based cohort study. BMC Med 2015;13:138.

14. Katz J, Zeger SL. Estimation of design effects in cluster surveys. Ann Epidemiol 1994;4:295-301.

15. Radloff LS. The CES-D Scale: a self-report depression scale for research in the general population. Appl Psychol Meas 1977;1:385-401.

16. de Silva VA, Ekanayake S, Hanwella R. Validity of the Sinhala version of the Center for Epidemiological Studies Depression Scale (CES-D) in out-patients. Ceylon Med J 2014;59:8-12.

17. Craig CL, Marshall AL, Sjöström M, et al. International physical activity questionnaire: 12-country reliability and validity. Med Sci Sports Exerc 2003;35:1381-95.

18. Arambepola C. Abdominal obesity and its association with selected risk factors of coronary heart disease in an adult population in the district of Colombo: University of Colombo, 2004.

19. United Nations Educational Scientific and Cultural Organization. International Standard Classification of Education ISCED 2011. Montreal, Quebec, Canada: Succursale Centre-Ville, 2012.

20. Weich S, Lewis G. Poverty, unemployment, and common mental disorders: population based cohort study. BMJ 1998;317:115-9.

21. Department of Census and Statistics. Sri Lanka standard classification of occupation (SLSCO-08). 2008.

22. International Labour Office. International Standard Classification of Occupations ISCO-08. 2012.

23. StataCorp. Stata 14 Stata Survey Data Reference Manual. College Station, TX: Stata Press, 2014.

24. Kojima G, Iliffe S, Taniguchi Y, et al. Prevalence of frailty in Japan: a systematic review and meta-analysis. J Epidemiol 2017;27.

25. von Elm E, Altman DG, Egger M, et al. The Strengthening the Reporting of Observational Studies in Epidemiology (STROBE) statement: guidelines for reporting observational studies. PLoS Med 2007:4:e296.

26. Biritwum RB, Minicuci N, Yawson AE, et al. Prevalence of and factors associated with frailty and disability in older adults from China, Ghana, India, Mexico, Russia and South Africa. Maturitas 2016;91:8-18.

27. Kashikar Y, Nagarkar A. Prevalence and determinants of frailty in older adults in India. Indian Journal of Gerontology 2016;30:364-81.

28. Devkota S, Anderson B, Soiza RL, et al. Prevalence and determinants of frailty and associated comorbidities among older Gurkha welfare pensioners in Nepal. Geriatr Gerontol Int 2017;17:2493-9.

29. Iwasaki M, Kimura Y, Sasiwongsaroj K, et al. Association between objectively measured chewing ability and frailty: a cross-sectional study in central Thailand. Geriatr Gerontol Int 2018;18:860-6.

30. World Health Organization. Countries, India. 2018. http://www.who. int/countries/ind/en/ (accessed 26 Feb 2018).

31. World Health Organization. Countries, Sri Lanka 2018. 2018. http:// www.who.int/countries/lka/en/.

32. Theou O, Brothers TD, Rockwood MR, et al. Exploring the relationship between national economic indicators and relative fitness and frailty in middle-aged and older Europeans. Age Ageing 2013;42:614-9.

33. Curcio CL, Henao GM, Gomez F. Frailty among rural elderly adults. BMC Geriatr 2014;14:2.

34. Moreno-Tamayo K, Manrique-Espinoza B, Rosas-Carrasco O, et al. Sleep complaints are associated with frailty in Mexican older adults in a rural setting. Geriatr Gerontol Int 2017;17:2573-8.

35. Çakmur H. Frailty among elderly adults in a rural area of Turkey. Med Sci Monit 2015;21:1232-42.

36. Theou O, Cann L, Blodgett J, et al. Modifications to the frailty phenotype criteria: systematic review of the current literature and investigation of 262 frailty phenotypes in the Survey of Health, Ageing, and Retirement in Europe. Ageing Res Rev 2015;21:78-94.

37. Moreira VG, Lourenco RA. Prevalence and factors associated with frailty in an older population from the city of Rio de Janeiro, Brazil: the FIBRA-RJ Study. Clinics 2013;68:979-85.

38. Cesari M, Prince M, Thiyagarajan JA, et al. Frailty: an emerging public health priority. J Am Med Dir Assoc 2016;17:188-92.

39. Feng $Z$, Lugtenberg $M$, Franse $C$, et al. Risk factors and protective factors associated with incident or increase of frailty among community-dwelling older adults: a systematic review of longitudinal studies. PLoS One 2017;12:e0178383.

40. Myers V, Drory Y, Goldbourt U, et al. Multilevel socioeconomic status and incidence of frailty post myocardial infarction. Int $J$ Cardiol 2014;170:338-43.

41. Ottenbacher KJ, Graham JE, Al Snih S, et al. Mexican Americans and frailty: findings from the Hispanic established populations epidemiologic studies of the elderly. Am J Public Health 2009;99:673-9.

42. Aranda MP, Ray LA, Snih SA, et al. The protective effect of neighborhood composition on increasing frailty among older Mexican Americans: a barrio advantage? J Aging Health 2011;23:1189-217.

43. McHugh JE, Dowling M, Butler A, et al. Psychological distress and frailty transitions over time in community-dwelling older adults. Ir J Psychol Med 2016;33:111-9.

44. UNICEF. The state of the world's children 2009. New York: United Nations Children's Fund, 2008.

45. Ministry of Health Nutrition and Indigenous Medicine, World Health Organization. Non communicable disease risk factor survey Sri Lanka 2015. 2015.

46. Dent E, Lien C, Lim WS, et al. The Asia-Pacific clinical practice guidelines for the management of frailty. J Am Med Dir Assoc 2017;18:564-75. 